\title{
Proaggregant nuclear factor(s) trigger rapid formation of $\alpha$-synuclein aggregates in apoptotic neurons
}

\author{
Peizhou Jiang ${ }^{1} \cdot$ Ming Gan $^{1} \cdot$ Shu-Hui Yen ${ }^{1} \cdot$ Simon Moussaud $^{1} \cdot$ Pamela J. McLean $^{1} \cdot$ \\ Dennis W. Dickson ${ }^{1} \mathbb{D}$
}

Received: 1 November 2015 / Revised: 25 January 2016 / Accepted: 26 January 2016 / Published online: 2 February 2016 (C) The Author(s) 2016. This article is published with open access at Springerlink.com

\begin{abstract}
Cell-to-cell transmission of $\alpha$-synuclein $(\alpha S)$ aggregates has been proposed to be responsible for progressive $\alpha \mathrm{S}$ pathology in Parkinson disease (PD) and related disorders, including dementia with Lewy bodies. In support of this concept, a growing body of in vitro and in vivo experimental evidence shows that exogenously introduced $\alpha \mathrm{S}$ aggregates can spread into surrounding cells and trigger PD-like pathology. It remains to be determined what factor(s) lead to initiation of $\alpha \mathrm{S}$ aggregation that is capable of seeding subsequent propagation. In this study we demonstrate that filamentous $\alpha \mathrm{S}$ aggregates form in neurons in response to apoptosis induced by staurosporine or other toxins-6-hydroxy-dopamine and 1-methyl-4-phenylpyridinium (MPP+). Interaction between $\alpha \mathrm{S}$ and proaggregant nuclear factor(s) is associated with disruption of nuclear envelope integrity. Knocking down a key nuclear envelop constituent protein, lamin B1, enhances $\alpha \mathrm{S}$ aggregation. Moreover, in vitro and in vivo experimental models demonstrate that aggregates released upon cell breakdown can be taken up by surrounding cells. Accordingly, we suggest that at least some $\alpha \mathrm{S}$ aggregation might be related to neuronal apoptosis or loss of nuclear membrane integrity, exposing cytosolic $\alpha$-synuclein to proaggregant nuclear factors. These findings provide new clues to the pathogenesis of PD and
\end{abstract}

Electronic supplementary material The online version of this article (doi:10.1007/s00401-016-1542-4) contains supplementary material, which is available to authorized users.

Dennis W. Dickson

dickson.dennis@mayo.edu

1 Neuropathology Laboratory, Department of Neuroscience, Mayo Clinic, 4500 San Pablo Road, Jacksonville, FL 32224, USA related disorders that can lead to novel treatments of these disorders. Specifically, finding ways to limit the effects of apoptosis on $\alpha \mathrm{S}$ aggregation, deposition, local uptake and subsequent propagation might significantly impact progression of disease.

Keywords Aggregation - Apoptosis $\cdot$ 6OHDA $\cdot$ Lamin $\mathrm{B} 1 \cdot \mathrm{MPP}+\cdot$ Nuclear membrane integrity $\cdot$ Parkinson's disease $\cdot$ Proaggregant nuclear factors $\cdot \alpha$-Synuclein

\section{Introduction}

Neuronal intracellular aggregates of $\alpha$-synuclein $(\alpha S)$ in Lewy bodies and Lewy neurites are pathological features of Parkinson's disease (PD) and related synucleinopathies such as dementia with Lewy bodies [1]. Although the mechanisms underlying $\alpha \mathrm{S}$ pathology remain unclear, the possibility that abnormal conformers of $\alpha \mathrm{S}$ may propagate from one cell to another has drawn increasing attention [2, 3]. Cell-to-cell propagation has been proposed to explain the spread of $\alpha \mathrm{S}$ pathology observed in cross-sectional studies of brains with a range of severity of PD pathology and conceptually organized into stages by Braak et al. [4]. The presence of $\alpha \mathrm{S}$ pathology in neurons of embryonic mesencephalic grafts implanted into the neostriatum to treat PD patients after a lag of about 10 years also supports the possibility that $\alpha \mathrm{S}$ spreads from host to graft $[5,6]$. In addition, a growing body of in vivo and in vitro experimental evidence supports the possibility that $\alpha \mathrm{S}$ can spread from cell to cell [7-11]. Inherent to this hypothesis is initial formation of "seeds" of abnormal $\alpha \mathrm{S}$ in selectively vulnerable neuronal populations, which subsequently propagate $[3,12]$. The origin of the seeds in experimental studies has been abnormal conformers of recombinant wild-type or 
mutant $\alpha \mathrm{S}$ or sonicated fractions "preformed fibrils" from post-mortem PD brains [8-10].

Neurodegeneration in PD and related disorders is a chronic, progressive process associated with neuronal cell death, associated energy failure and disruption of cellular integrity, which are features of cells undergoing apoptosis [13]. Evidence from postmortem brains of PD [14, 15], animal models of PD [16, 17], as well as in vitro cell culture studies $[18,19]$ strongly suggest that $\alpha S$-associated neuronal death is apoptotic. Moreover, there is evidence for a proapoptotic environment in the substantia nigra in PD [14]. The identification of high-molecular-weight $\alpha \mathrm{S}$ species in cells expressing $\alpha \mathrm{S}$ subjected to apoptosis [20,21] prompted us to investigate if $\alpha \mathrm{S}$ aggregation is induced by apoptosis and to determine factor(s) that promote patho$\operatorname{logic} \alpha \mathrm{S}$ aggregation, which may be seeds for eventual cellto-cell transmission.

In the present study, we employed cell- and animalbased studies to explore mechanisms of $\alpha \mathrm{S}$ aggregation in apoptotic neurons. We demonstrate that filamentous $\alpha \mathrm{S}$ aggregates rapidly form in apoptotic neurons through an interaction between $\alpha \mathrm{S}$ and proaggregant nuclear factor(s) following disruption of the nuclear envelope. Moreover, $\alpha \mathrm{S}$ aggregates released upon cell breakdown can be taken up by surrounding cells in both in vitro and in vivo experimental models. These data support the possibility that loss of nuclear membrane integrity plays an important role in $\alpha \mathrm{S}$ pathology.

\section{Materials and methods}

\section{Cell culture and maintenance}

We used a dopaminergic neuronal cell model, BE(2)M17D/3D5, which is derived from human neuroblastoma BE(2)-M17D cell line [22] that expresses human wildtype $\alpha \mathrm{S}$ upon TetOff induction and displays neuronal phenotypes under retinoic acid-induced differentiation [23]. $\mathrm{BE}(2)-\mathrm{M} 17 \mathrm{D} / 3 \mathrm{D} 5$ cells were maintained in DMEM/10 \% fetal bovine serum with $2 \mu \mathrm{g} / \mathrm{ml}$ Tet at $37{ }^{\circ} \mathrm{C}$ and $5 \%$ $\mathrm{CO} 2$. Cells were seeded at the density of $3 \times 10^{6}$ cells/ plate $(100 \times 20 \mathrm{~mm}, \mathrm{BD}$ Biosciences, San Jose, CA $)$ or $5.0 \times 10^{5}$ cells/well in 6-well plates for biochemical analysis, and $2 \times 10^{4}$ cells/well on coverslips in 24-well plates for immunocytochemistry. For differentiation and $\alpha \mathrm{S}$ induction, media were replaced with Neurobasal medium (Invitrogen, Thermo Fisher, Waltham, MA), $2 \%$ B-27 supplement (Invitrogen, Thermo Fisher), $2 \mathrm{mM}$ L-glutamine (Sigma-Aldrich, Saint Louis, MO) and $10 \mu \mathrm{M}$ RA (Sigma-Aldrich).

A previously described $\mathrm{H} 4$ neuroglioma cell line that inducibly co-expresses the $\mathrm{N}$-terminal half of Venus
YFP tagged to $\alpha \mathrm{S}$ (V1S) and C-terminal half of Venus YFP tagged $\alpha S$ (SV2) upon TetOff induction, named as H4/V1S-SV2 [24], were maintained in OPTI-MEM (Invitrogen) medium supplemented with $10 \%$ fetal bovine serum (Invitrogen), $200 \mu \mathrm{g} / \mathrm{ml}$ Hygromycin $\mathrm{B}, 200 \mu \mathrm{g} / \mathrm{ml} \mathrm{G} 418$ and $2 \mu \mathrm{g} / \mathrm{ml}$ Tet and incubated at $37^{\circ} \mathrm{C}$.

The Lund human mesencephalic (LUHMES) cell line (LUHMES ATCC ${ }^{\circledR}$ CR-2927) is a subclone of the Tetcontrolled, v-myc-overexpressing human mesencephalicderived cell line. It can be differentiated into dopaminelike neurons [25]. Cells were cultured in advanced DMEM/F-12/Glutamax medium supplemented with $\mathrm{N} 2$ supplement (Invitrogen) and $40 \mathrm{ng} / \mathrm{ml} \mathrm{FGF} 2$ (R\&D Systems, Minneapolis, MN) at $37{ }^{\circ} \mathrm{C}$ according to published methods [26]. Culture plates were pre-coated with $50 \mu \mathrm{g} / \mathrm{ml}$ poly-L-ornithine (Sigma-Aldrich) and $1 \mu \mathrm{g} / \mathrm{ml}$ fibronectin (Sigma-Aldrich, F1141). For differentiation, media were replaced with advanced DMEM/F-12/Glutamax/N2 medium (Invitrogen) containing $2 \mathrm{ng} / \mathrm{ml}$ human recombinant glial cell-derived neurotrophic factor (R\&D Systems), $1 \mathrm{mM}$ cAMP (Sigma-Aldrich) and $1 \mu \mathrm{g} / \mathrm{ml}$ Tet for 4 days.

For primary cultures, cortical/hippocampal neurons from embryonic C57BL/6 wild-type mice were seeded on poly-D-lysine (Sigma-Aldrich) coated 6-well plate at about $1 \times 10^{6}$ cells per well. Experimental protocols for primary cultures were the same as those reported previously [27].

\section{Lentiviral plasmids and virus preparation}

Lentiviral plasmids carrying $\alpha \mathrm{S}$ (EX-G0543-Lv105) were purchased from Genecopoeia, Rockville, MD, and shRNAs of human LMNB1 were purchased from Sigma-Aldrich. The preparation of Lentivirus carrying genes of interest or shRNA was the same as described previously [28].

\section{Isolation of nuclear and cytoplasmic fractions}

Nuclear and cytoplasmic fractions were isolated using NEPER nuclear and cytoplasmic extraction reagents (Thermo Scientific, Waltham, MA) following the manufacturer's instructions, but with some modifications. Briefly, cells were resuspended in cytoplasmic extraction reagent I, incubated for $10 \mathrm{~min}$, followed by the addition of cytoplasmic extraction reagent II and centrifugation at $16000 \times g$ for $5 \mathrm{~min}$. Supernatant was kept as cytoplasmic fraction. The insoluble pellet was further mixed with nuclear extraction reagent and subjected to sonication for 3 min followed by centrifugation at $16000 \times g$ for $10 \mathrm{~min}$. The supernatant was then kept as nuclear fraction. The whole process was done on ice or at $4{ }^{\circ} \mathrm{C}$. The bicinchoninic acid (BCA) assay was used for protein quantitation. 


\section{Isolation of apoptotic bodies}

Apoptotic bodies were isolated according to a previously reported protocol [29]. Medium from 10 plates $(100 \times 20 \mathrm{~mm})$ of apoptotic neurons was collected and clarified from dead cells and cell debris by centrifugation $(800 \times g, 10 \mathrm{~min})$. The apoptotic body-enriched supernatant was further centrifuged $(16000 \times g, 20 \mathrm{~min})$ to generate a final pellet containing apoptotic bodies. The pellet was either stored at $-80{ }^{\circ} \mathrm{C}$ for future use or resuspended immediately in PBS.

\section{Fractionation studies of apoptotic bodies and electron microscopy}

Apoptotic bodies were fractionated to derive $1 \%$ sarkosylinsoluble material following previously reported protocols [27]. The sarkosyl-insoluble material was resuspended in $50 \mathrm{mM}$ Tris ( $\mathrm{pH} \mathrm{8.0)}$ and used for electron microscopy and immunoelectron microscopy as described previously [30].

\section{Sample preparation and western blot analysis}

Cell cultures were harvested and centrifuged at $200 \times g$ for $15 \mathrm{~min}$. The pellets were resuspended in MES buffer (20 mM MES, pH 6.8; $80 \mathrm{mM} \mathrm{NaCl}, 1 \mathrm{mM} \mathrm{MgCl}, 2 \mathrm{mM}$ EGTA, $10 \mathrm{mM} \mathrm{NaH}_{2} \mathrm{PO}_{4}, 20 \mathrm{mM} \mathrm{NaF}$, phenylmethylsulfonyl fluoride PMSF, $1 \mu \mathrm{g} / \mathrm{ml}$ and leupeptin, $10 \mu \mathrm{g} / \mathrm{mL}$ ) [22] supplemented with phosphatase inhibitors and then sonicated for $1 \mathrm{~min}$, followed by centrifugation at $180 \times g$ for $15 \mathrm{~min}$. The whole process was done at $4{ }^{\circ} \mathrm{C}$. The cell lysates were mixed with $6 \times$ SDS-PAGE sample buffer (375 mM Tris-HCl, $12 \%$ SDS, $60 \%$ Glycerol, $12 \% 2-$ Mercaptoethanol, $0.03 \%$ Bromophenol blue), boiled for $10 \mathrm{~min}$ and resolved by SDS-PAGE using 10-20\% Tris/ Glycine gel (Bio-Rad, Hercules, California). Precision Plus protein standards (Bio-Rad) were included as references. After gel electrophoresis, proteins were transferred onto polyvinylidene difluoride (PVDF) membranes. Antibodies used for western blot studies are as follows: total $\alpha \mathrm{S}$ (Syn1; mouse monoclonal IgG1; cat. \#: 610787) from BD Bioscience; phospho-serine-129 $\alpha \mathrm{S}$ (pSyn \#64, mouse IgG1; cat \#: 015-25191) from Wako USA, Richmond, VA; pore membrane protein of $121 \mathrm{kDa}(\mathrm{POM} 121)(\mathrm{N} 2 \mathrm{~N} 3$, rabbit polyclonal; cat \#: GTX102128) from GeneTex, Irvine, CA; lamin B1 (LMNB1) (rabbit polyclonal; cat \#: 129871-AP) from Proteintech, Rosemont, IL; Histone H3 (rabbit polyclonal; cat \# ab1791) from Abcam, Cambridge, MA; cleaved caspase 3 (rabbit polyclonal to human cleaved caspase 3 (Asp175); cat \#: 9661) from Cell Signaling, Danvers, MA; $\alpha$-tubulin (rabbit monoclonal; Epitomics cat \#: 1878-1) from Abcam, Cambridge, MA; and $\beta$-actin (mouse monoclonal IgG2a; cat \#: A5316) from Sigma, Saint Louis,
MO (A5316). Western Lightning Plus ECL (PerkinElmer, Bridgeville, PA) or ECL ${ }^{\mathrm{TM}}$ Prime Western Blotting Detection Reagent (Fisher Scientific, Pittsburgh, PA) was used for visualization of protein immunoreactivities. The results of western blots were quantified using ImageJ software. Expression levels of proteins of interest were normalized to internal control. Data from at least 3 sets of independent experiments were analyzed by one-way ANOVA with Dunnett's post hoc test for statistical significance.

\section{Time-lapse confocal microscopy imaging}

H4/V1S-SV2 cells with $\alpha \mathrm{S}$ induction for 5 days were cultured in reduced serum medium (Cat. No. 31985-062, Invitrogen) in Lab-Tek ${ }^{\mathrm{TM}}$ Chambered Cover Glass System (4 well, Nunc ${ }^{\mathrm{TM}}$ Lab-Tek II, Sigma-Aldrich). After exposure to staurosporine (STS), cells were subjected to time lapse imaging (interval time $=10 \mathrm{~min}, 16 \mathrm{~h}$ for early or $36 \mathrm{~h}$ for later stage of apoptosis) by confocal microscopy (Zeiss LSM 510, Carl Zeiss MicroImaging, Pleasanton, CA) at $37{ }^{\circ} \mathrm{C}$ to monitor formation and distribution of $\alpha \mathrm{S}$ aggregates. Three independent experiments were performed to confirm the results. In each experiment, 5 fields (upper left, upper right, center, lower left and lower right) with at least 90 cells were chosen for counting the ratio of cells having predominant $\alpha \mathrm{S}$ aggregation in nuclei after $16 \mathrm{~h}$ of STS treatment.

\section{Immunocytochemistry}

Cells grown on cover slips were rinsed with PBS, fixed in $4 \%$ paraformaldehyde and permeabilized with $0.1 \mathrm{M}$ Tris-buffered saline (TBS; pH 7.6) containing $0.5 \%$ Triton X-100 for $5 \mathrm{~min}$. They were subsequently blocked with $3 \%$ goat serum in TBS, incubated with primary antibodies (rabbit anti-Flag from Sigma Aldrich, mouse anti-Myc from cell signaling, or LB509 from Invitrogen) in TBS containing $1 \%$ goat serum overnight at $4{ }^{\circ} \mathrm{C}$ and then incubated for $1 \mathrm{~h}$ with secondary antibodies. Immunolabeled cells were stained with nuclear stain DAPI (Invitrogen) for 10 min and observed by confocal fluorescence microscopy (Zeiss LSM 510, Carl Zeiss MicroImaging, Pleasanton, CA). Three independent experiments were performed to confirm the results. For each in situ cell uptake experiment, at least $60 \alpha$ S-Flag cells were included for counting of cells bearing particles positive with Myc and Flag tags.

\section{Stereotaxic surgery}

All animal procedures were approved by the Mayo Clinic Institutional Animal Care and Use Committee. C57BL/6 mice (12 months of age) were anesthetized with $3 \%$ isoflurane and stereotaxically injected with different samples. For cell 
lysates and apoptotic bodies, $20 \mu \mathrm{g}$ total protein per brain was injected. Control mice were injected with PBS to exclude any effects due to surgery and injection. A single-needle insertion (coordinates: $X=2.0 \mathrm{~mm} ; Y=0.2 \mathrm{~mm} ; Z=0.8$ and $2.6 \mathrm{~mm}$, respectively) into the left forebrain was used to deliver the inoculum to somatosensory cortex and dorsal neostriatum. Material was injected via a Hamilton syringe at a rate of $0.5 \mu 1$ per min $(5 \mu 1$ total per site). After recovery from surgery, animals were monitored regularly. A week later, animals were subjected to transcardial perfusion with PBS, and brains were fixed in $10 \%$ formalin followed by paraffin embedding. Coronal sections were cut at 5-micron thickness for immunohistochemical and immunofluorescent staining.

\section{Thioflavin $\mathrm{T}$ binding}

Apoptotic bodies were resuspended in TBS at $\mathrm{pH} 7.4$ and $10 \mu \mathrm{M}$ Thioflavin T. Fluorescence was measured immediately at $440 \mathrm{~nm}$ (excitation)/460-600 nm (emission) with a Cary Eclipse fluorescence spectrophotometer (Varian, Palo Alto, CA). After subtraction of background signals from reagent alone, the fluorescent signals from the peak areas were integrated [31].

\section{Immunohistochemical and immunofluorescent staining}

Sections of paraffin-embedded tissue were sequentially subjected to deparaffinization, rehydration, steaming in DAKO target retrieval solution $\mathrm{pH} 6.1$ for $30 \mathrm{~min}$, digestion with Protease 24 for $8 \mathrm{~min}$ at room temperature (only for staining with LB509) and blocking with Protein Block (X0909, DAKO, Carpinteria, CA) for $1 \mathrm{~h}$ at room temperature. For immunoperoxidase labeling, sections were treated with $3 \%$ hydrogen peroxide to block endogenous peroxidase and then incubated with $5 \%$ normal goat serum for $20 \mathrm{~min}$ to reduce non-specific labeling. Tissue sections were incubated with antibodies to $\alpha \mathrm{S}$ (LB509, 1:100, Invitrogen) for 45 min and Envision-Plus labeled polymer HRP, rabbit or mouse (DAKO) for $30 \mathrm{~min}$. Peroxidase labeling was visualized with a solution containing $3,3^{\prime}$-diaminobenzidine (DAB-Plus). The sections were subsequently counterstained with Lerner 1 hematoxylin (14-930-11, Fisher Scientific) and coverslipped with cytoseal mounting medium (8310-16, Richard-Allan Scientific, Kalamazoo, MI). For immunofluorescence, sections were incubated with Protein Block (X0909, DAKO) for $1 \mathrm{~h}$ at room temperature. The sections were incubated with antibodies to MAP2 (1:1000, chicken polyclonal, EnCor Biotechnology, Gainesville, FL) and $\alpha \mathrm{S}$ (LB509, 1:100, Invitrogen) at $4{ }^{\circ} \mathrm{C}$ overnight, followed by $1.5 \mathrm{~h}$ of incubation with secondary antibodies (1:500) after washing. Non-specific fluorescence signals were blocked by staining with Sudan Black. Sections were coverslipped with Vectashield mounting media (H-1200, Vector Laboratories, Burlingame, CA) and viewed with confocal microscopy.

\section{Results}

\section{Induction of insoluble $\alpha \mathrm{S}$ in cellular models by apoptosis}

To determine if apoptosis can trigger intracellular $\alpha \mathrm{S}$ aggregation, staurosporine (STS), a well-known neuronal apoptosis inducer, was used to treat differentiated $\mathrm{BE}(2)$ M17D/3D5 cells because it has been shown that exposure of neurons to 30-100 nM STS can induce concentrationdependent apoptotic degeneration [32]. As expected, BE(2)-M17D/3D5 cells exposed to 50 or $100 \mathrm{nM}$ STS showed time- and dose-dependent increases in both cleaved caspase 3, a molecular marker of apoptosis, and in SDSresistant aggregated $\alpha \mathrm{S}$ (Fig. 1). $\alpha \mathrm{S}$ aggregation was observed as early as $4 \mathrm{~h}$ after exposure to STS (Fig. 1c, e), indicating that factor(s) associated with apoptosis rapidly trigger pathologic assembly of $\alpha \mathrm{S}$. Pretreatment with a caspase inhibitor (CI)-Z-VAD-FMK, a cell-permeant pancaspase inhibitor that irreversibly binds to the catalytic site of caspase proteases, significantly reduced both caspase activation and $\alpha \mathrm{S}$ aggregation (Fig. 1c, e), confirming that apoptosis contributes to formation of $\alpha \mathrm{S}$ aggregates.

To determine whether $\alpha \mathrm{S}$ aggregation in response to apoptosis is unique to $\mathrm{BE}(2)-\mathrm{M} 17 \mathrm{D} / 3 \mathrm{D} 5$ cells, we included two other cell models, differentiated LUHMES cells (Fig. 2a) and primary mouse cortical neurons (Fig. 2b). Since increased levels of $\alpha \mathrm{S}$ can accelerate aggregation [33], the two cell models were infected with lentivirus carrying human $\alpha \mathrm{S}$ to increase its expression. In both cell models SDS-resistant $\alpha \mathrm{S}$ aggregates formed after STS treatment in a time-dependent manner, and pretreatment with the caspase inhibitor blocked both apoptosis and $\alpha \mathrm{S}$ aggregation (Fig. 2).

To further determine if apoptosis-triggered $\alpha \mathrm{S}$ aggregation has physiological relevance, we used STS to treat primary neurons bearing only endogenous $\alpha \mathrm{S}$. As a positive control, we included sibling cultures infected with lentivirus carrying human $\alpha \mathrm{S}$. The results showed that endogenous $\alpha \mathrm{S}$ (EN) can also form aggregates in response to STS treatment, but the magnitude of aggregation is much less compared to that in neurons overexpressing $\alpha \mathrm{S}$ (EX) with lentivirus infection (Fig. 2c).

\section{Fluorescent complementation shows $\alpha \mathrm{S}$ aggregates in nuclei during induction of apoptosis}

To study dynamic changes in $\alpha \mathrm{S}$ aggregation during apoptosis, a fluorescence complementation assay with the $\mathrm{H} 4$ / 

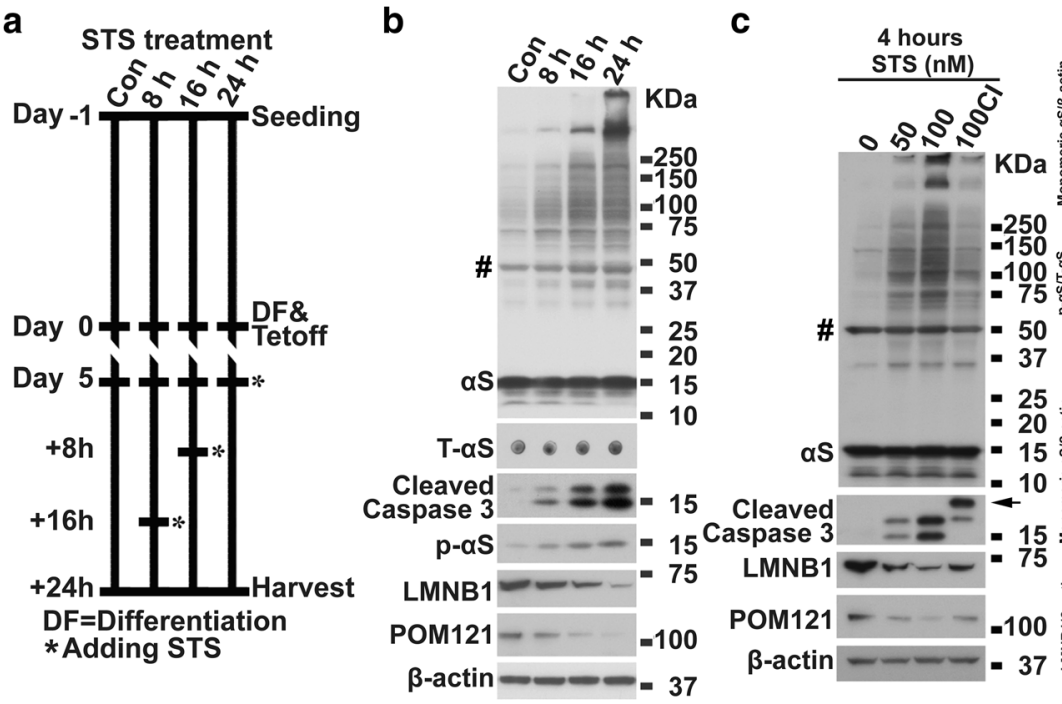

\section{d}
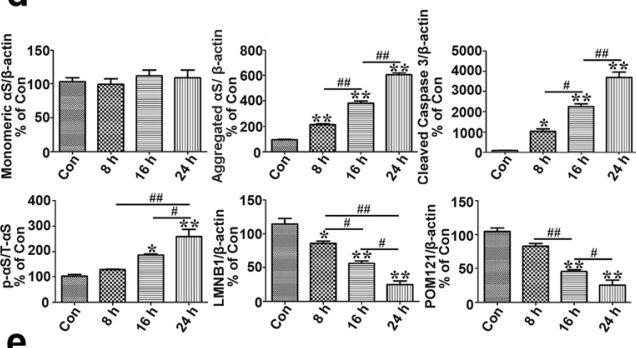

$37 \mathrm{e}$

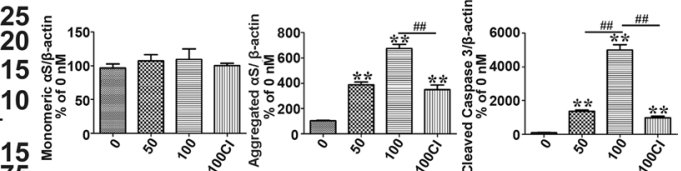

$\mathrm{DF}=$ Differentiation

*Adding STS

-actin

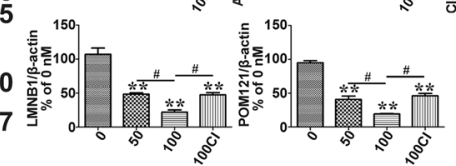

Fig. 1 Apoptosis induces $\alpha \mathrm{S}$ aggregation and phosphorylation in $\mathrm{BE}(2)-\mathrm{M} 17 \mathrm{D} / 3 \mathrm{D} 5$ cells. a The basic paradigm for cell differentiation, $\alpha \mathrm{S}$ induction and staurosporine (STS) treatment. BE(2)-M17D/3D5 cells with 5 days of differentiation and $\alpha \mathrm{S}$ induction were exposed to $25 \mathrm{nM}$ STS for $0,8,16$ and $24 \mathrm{~h}$ before harvest. b STS treatment of $\mathrm{BE}(2)-\mathrm{M} 17 \mathrm{D} / 3 \mathrm{D} 5$ cells induces apoptosis, $\alpha \mathrm{S}$ aggregation and Serine 129 phosphorylation, and degradation of lamin B1 (LMNB1) and nuclear pore membrane protein $121 \mathrm{KDa}$ (POM121) in a timedependent manner. c High dose of STS treatment can rapidly trigger apoptosis and other aforementioned effects which can be significantly prevented by caspase inhibitor. BE(2)-M17D/3D5 cells with 5 days of differentiation and $\alpha \mathrm{S}$ induction were exposed to 50 and $100 \mathrm{nM}$ for $4 \mathrm{~h}$ before harvest. A group of $100 \mathrm{nM}$ STS-treated sibling cultures was pretreated with caspase inhibitor (CI). All cell lysates were subjected to SDS-PAGE followed by western blotting with antibod-

V1S-SV2 cell line was used. This cell line expresses $\alpha \mathrm{S}$ tagged with a split Venus YFP molecule. Binding of V1S to SV2 upon $\alpha S-\alpha S$ interaction can reconstitute fluorescence and indicates $\alpha \mathrm{S}$ aggregation [24]. After 5 days of induction, H4/V1S-SV2 cells were exposed to $25 \mathrm{nM}$ STS and subjected to time-lapse confocal microscopy to monitor $\alpha \mathrm{S}$ aggregation. Unexpectedly, after $16 \mathrm{~h}$ of STS treatment, most cells $(91 \pm 3 \%)$ showed predominant fluorescent signals in nuclei, suggesting that the nuclear environment in neurons undergoing apoptosis favors $\alpha \mathrm{S}$ aggregation. At later stages of apoptosis, associated with nuclear condensation, $\alpha \mathrm{S}$ aggregates were detected in the cytoplasm, and finally they were released into the media, where some bound to nearby cells (Fig. 3a, b).

\section{Apoptosis-induced $\alpha \mathrm{S}$ aggregates are found in nuclear and cytoplasmic fractions}

To support findings from live cell imaging, we performed nuclear and cytoplasmic protein fractionation of STS-treated neuronal cultures. The BE(2)-M17D/3D5 human dopaminergic cell line was chosen because it ies to interesting proteins. Dot blotting of cell lysates was used to detect total $\alpha \mathrm{S}$ level (T- $\alpha \mathrm{S})$ for quantification of $\mathrm{p}-\alpha \mathrm{S} / \mathrm{T}-\alpha \mathrm{S}$ immunoreactivities. Molecular weight standards were included as references. Arrow denotes a specific cleaved caspase 3 band in BE(2)-M17D/3D5 cells pretreated with caspase inhibitor. Number sign (\#) denotes a non-specific Syn1-immunoreactive band on western blots of lysates from BE(2)-M17D/3D5 cells. d, e Statistical analysis of immunoreactivity of various proteins shown in (b and $\mathbf{c})$. Bar graphs in $\mathbf{d}$ and e summarize the results of quantitative analyses of immunoreactivities of various proteins in cell lysates from three independent experiments represented by $\mathbf{b}$ and $\mathbf{c}$ with normalization against $\beta$-actin or $\mathrm{T}-\alpha \mathrm{S}$ immunoreactivities. The average values of control group (Con or $0 \mathrm{nM}$ ) were set as $100 \%$. Error bars represent standard error of the mean $(* p<0.05$, ** $p<0.01$, comparing to control; $\# p<0.05$, $\# \# p<0.01$, comparing subsets linked by line, $n=3$ )

inducibly expresses wild-type human $\alpha \mathrm{S}$ at a high level amenable to biochemical analyses [23]. Differentiated $\mathrm{BE}(2)-\mathrm{M} 17 \mathrm{D} / 3 \mathrm{D} 5$ cells with 5 days of $\alpha \mathrm{S}$ induction were collected at various time points following exposure to STS. Nuclear and cytoplasmic fractions were prepared and analyzed with dot blots, as well as with sodium dodecyl sulfate polyacrylamide gel electrophoresis (SDS-PAGE) western blots. As expected, dot blots revealed more $\alpha \mathrm{S}$ in cytoplasmic than nuclear fractions (Fig. 3c, Supplementary Fig. A1), consistent with previous study results showing that $\alpha \mathrm{S}$ is predominantly a cytoplasmic protein. Total $\alpha \mathrm{S}$ progressively increased in the nuclear fraction following induction of apoptosis with STS, suggesting that $\alpha \mathrm{S}$ translocates to the nucleus with apoptosis. Western blots showed that the cytoplasmic fraction had much more monomeric $\alpha S$ than the nuclear fraction when the same amount of total proteins from each fraction were compared; whereas higher molecular weight $\alpha \mathrm{S}$ aggregates are more apparent in nuclear compared to cytoplasmic fractions (Fig. 3c, Supplementary Fig. A1). These results suggest that the nuclear fraction contains factor(s) that promote $\alpha \mathrm{S}$ assembly. Moreover, $\alpha \mathrm{S}$ aggregation increases in a time-dependent manner after induction 

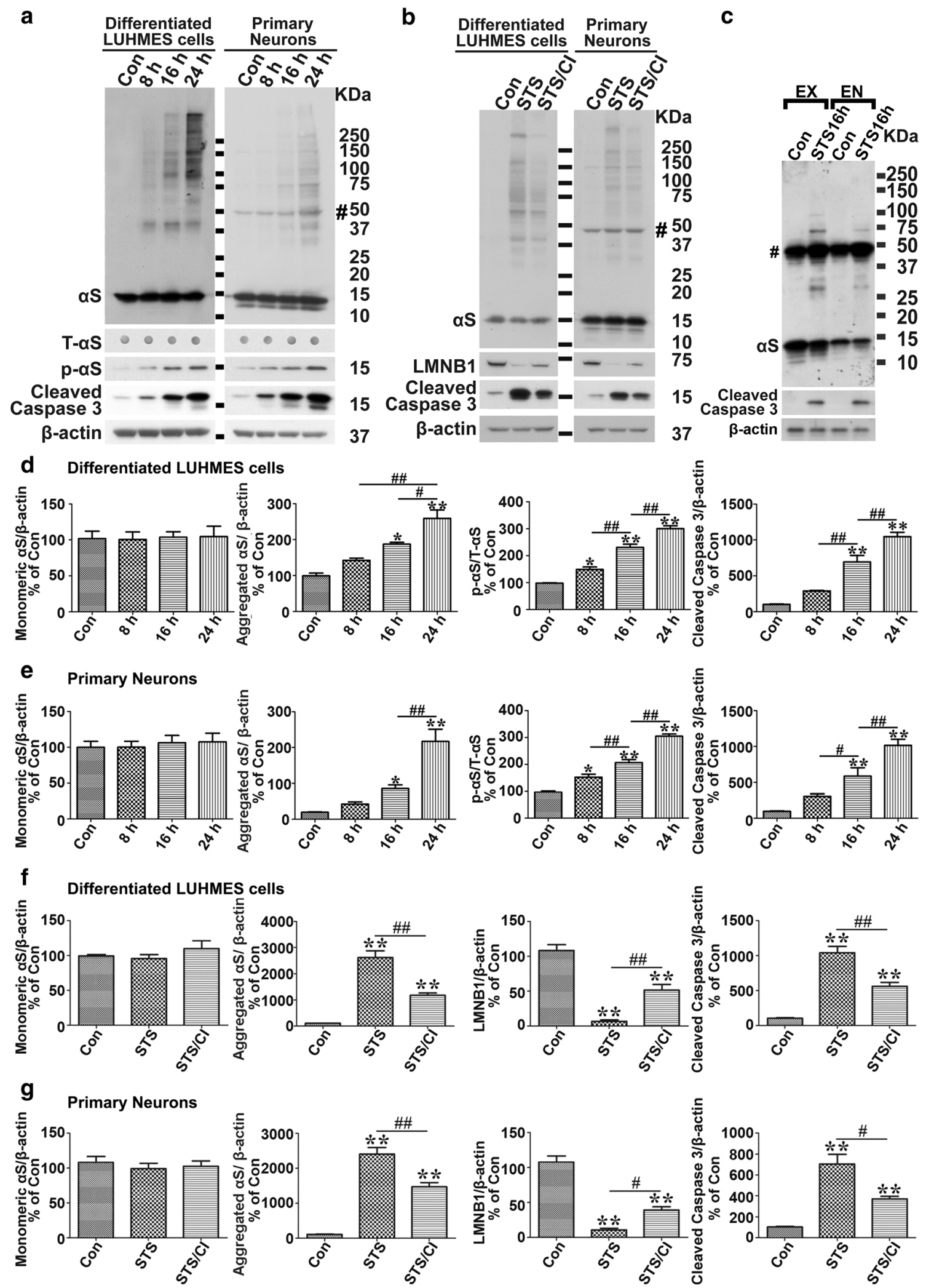
4Fig. 2 Apoptosis induces $\alpha \mathrm{S}$ aggregation and phosphorylation in differentiated LUHMES and primary neurons. a STS treatment induces apoptosis, $\alpha \mathrm{S}$ aggregation and phosphorylation in a time-dependent manner in differentiated LUHMES cells and primary neurons. Differentiated LUHMES cells and primary neuronal cultures overexpressing $\alpha \mathrm{S}$ via infection with lentivirus carrying $\alpha \mathrm{S}$ were, respectively, exposed to $100 \mathrm{nM}$ STS for $0,8,16$ and $24 \mathrm{~h}$ before being harvested. b Caspase inhibitor (CI) prevents STS-induced apoptosis and $\alpha \mathrm{S}$ aggregation in differentiated LUHMES cells and primary neuronal cultures. Cultures without STS treatment were used as control (Con). STS-treated sibling cultures were pretreated with caspase inhibitor $(\mathrm{STS} / \mathrm{CI})$ to inhibit apoptosis. c Apoptosis induces aggregation of endogenous $\alpha \mathrm{S}$ in mouse primary cultures. Primary neuronal cultures with only endogenously expressed $\alpha \mathrm{S}$ (EN) or with exogenously overexpression of $\alpha \mathrm{S}$ (EX) via infection with lentivirus carrying $\alpha \mathrm{S}$ were exposed to $100 \mathrm{nM}$ STS or vehicle (Con) for $16 \mathrm{~h}$ before harvest. All cell lysates were subjected to SDS-PAGE followed by western blotting with antibodies to proteins of interesting. Dot blotting of cell lysates was used to detect the total $\alpha \mathrm{S}$ level (T- $\alpha \mathrm{S})$ for quantification of $\mathrm{p}-\alpha \mathrm{S} / \mathrm{T}-\alpha \mathrm{S}$ immunoreactivities. Molecular weight standards were included as references. Number sign (\#) denotes a non-specific Syn1-immunoreactive band on western blots of lysates from primary cultures. d-g Statistical analyses of immunoreactivities of various proteins shown in a and b. Bar graphs in $\mathbf{d}-\mathbf{g}$ summarize results of quantitative analyses of immunoreactivities of various proteins in cell lysates from three independent experiments represented by a left, $\mathbf{a}$ right, $\mathbf{b}$ left and $\mathbf{b}$ right with normalization against $\beta$-actin or $\mathrm{T}-\alpha \mathrm{S}$ immunoreactivities. The average values of control group (Con) were set as $100 \%$. Error bars represent standard error of the mean $(* p<0.05, * * p<0.01$, comparing to control; \#p $<0.05, \# \# p<0.01$, comparing subsets linked by line, $n=3$ )

of apoptosis in both nuclear and cytoplasmic fractions (Fig. 3c, Supplementary Fig. A1). Since translocation of $\alpha \mathrm{S}$ to the nucleus persisted during apoptosis, it was not surprising to see progressive increase of $\alpha \mathrm{S}$ aggregation in the nuclear fraction with progression of apoptosis. It was not immediately clear why aggregation of cytoplasmic $\alpha \mathrm{S}$ also increases with progression of apoptosis; however, it is possible that nuclear factor(s) promoting aggregation may translocate from nucleus into the cytoplasm given that a representative nuclear protein (histone H3, Fig. 3c) gradually increases in cytoplasmic fractions with progression of apoptosis (Supplementary Fig. A1).

\section{Nuclear factor(s) that promote $\alpha \mathrm{S}$ assembly shift to cytoplasm with apoptosis}

To confirm the role of nuclear factor(s) in facilitating $\alpha \mathrm{S}$ aggregation, the same amount of protein $(50 \mu \mathrm{g})$ from nuclear and cytoplasmic fractions of differentiated null M17D cells (without $\alpha$ S overexpression) with or without 8 and $16 \mathrm{~h}$ of STS treatment was incubated with freshly prepared recombinant $\alpha \mathrm{S}(10 \mu \mathrm{g})$ as described previously [30] for $30 \mathrm{~min}$ at $37^{\circ} \mathrm{C}$. At baseline, $\alpha \mathrm{S}$ aggregates were minimal-to-nonexistent when recombinant $\alpha \mathrm{S}$ was mixed with either cytoplasmic fraction buffer or nuclear fraction buffer, but $\alpha \mathrm{S}$ aggregates rapidly appeared in preparations exposed to nuclear fractions from both STS-treated and non-treated cells (Fig. 3e, Supplementary Fig. A1), supporting the presence of nuclear factor(s) that facilitate $\alpha \mathrm{S}$ aggregation. Interestingly, in STS-treated cells, the effect of cytoplasmic fraction on $\alpha \mathrm{S}$ aggregation was positively correlated with the duration of treatment, consistent with the hypothesis that as apoptosis progresses, proaggregant nuclear factor(s) increasingly gain access to cytoplasm.

\section{Disruption of nuclear envelope integrity during apoptosis and $\alpha \mathrm{S}$ aggregation}

Given that nuclear envelopes block free passage of molecules between nucleus and cytoplasm and that apoptosis is associated with degradation of the nuclear envelope [34], we hypothesized that progressive increases in nuclear proaggregant factor(s) in the cytoplasm would correlate with disruption of the nuclear envelope. We addressed this by measuring the status of two key proteins of the nuclear envelope, pore membrane protein of $121 \mathrm{kDa}$ (POM121) and lamin B1 (LMNB1), in STStreated neuronal cultures for their relation to increases in $\alpha \mathrm{S}$ aggregation (Fig. 1b, c).

We postulated that neurons with compromised nuclear envelope integrity due to decreased expression of key structural components of nuclear membrane would have increased susceptibility to STS and that $\alpha \mathrm{S}$ aggregation would be increased in such cells. To test whether compromised nuclear envelope can trigger $\alpha \mathrm{S}$ aggregation, neurons were subjected to knockdown of LMNB1 using lentivirus delivered shRNA, followed by STS or vehicle treatment. We found neurons deficient in LMNB1 (expressing less than $20 \%$ of control levels) had significantly more $\alpha \mathrm{S}$ aggregates than cultures exposed to the same dose of lentivirus carrying control vector (Fig. 3g, Supplementary Fig. A1), suggesting that loss of nuclear envelope integrity was associated with increased vulnerability to $\alpha \mathrm{S}$ aggregation. Cultures with LMNB1 knockdown to around $50 \%$ of control had similar expression of $\alpha \mathrm{S}$ as controls, but they had significantly more $\alpha \mathrm{S}$ aggregates than controls at the same dose and duration of STS treatment, suggesting that neurons with deficient constituent proteins of nuclear envelope are more vulnerable to $\alpha \mathrm{S}$ aggregation.

\section{Phospho-serine 129 in $\alpha \mathrm{S}$ aggregates of apoptotic neurons}

Because phosphorylated $\alpha \mathrm{S}$ (p- $\alpha \mathrm{S}$ ) accumulates in Lewy bodies and Lewy-related pathology [35], we immunostained apoptosis-induced $\alpha \mathrm{S}$ aggregates for the presence of this post-translational modification. Western blots of cell lysates from differentiated BE(2)-M17D/3D5 cells, as well as LUHMES cells and primary neurons subjected to 
a

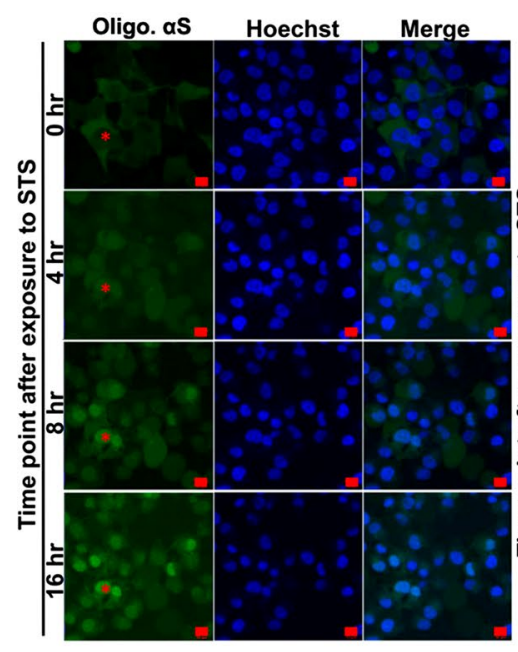

b

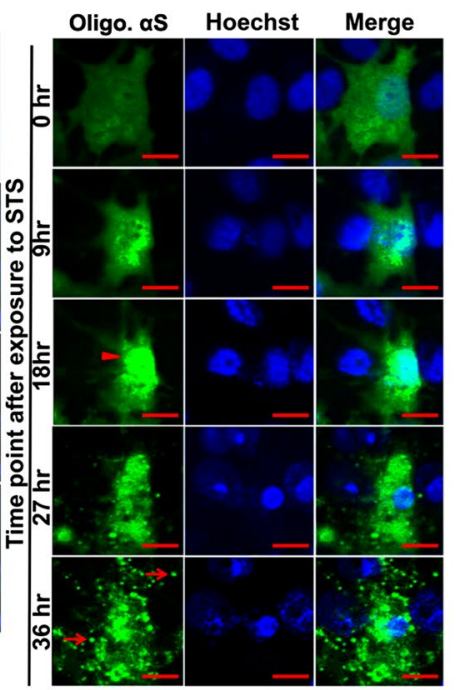

f
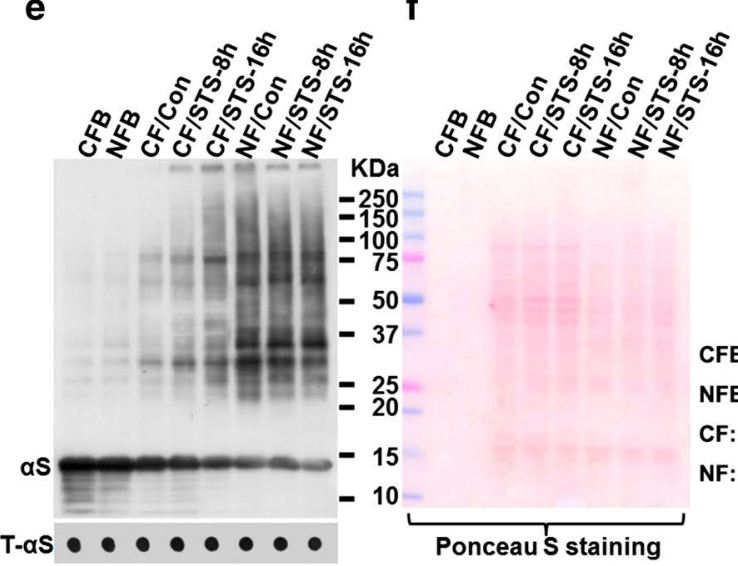

cos

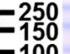

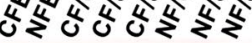

C

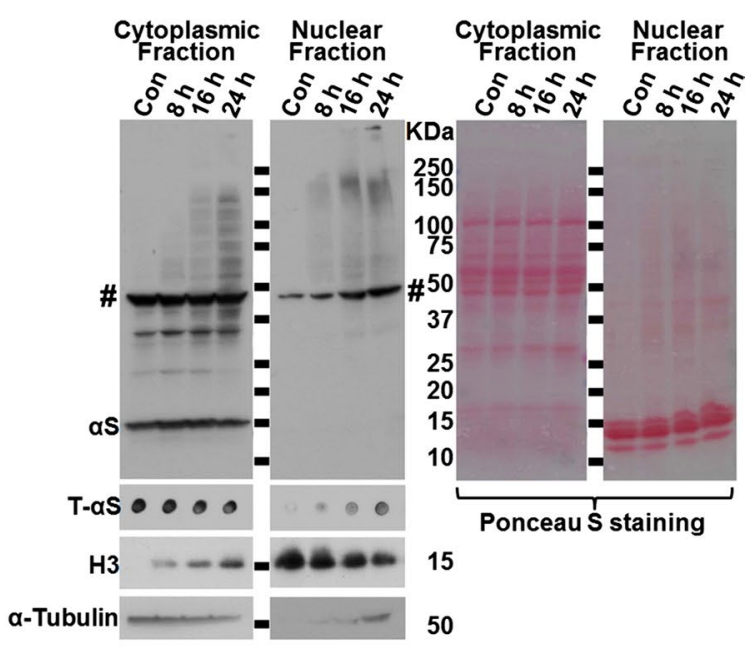

d
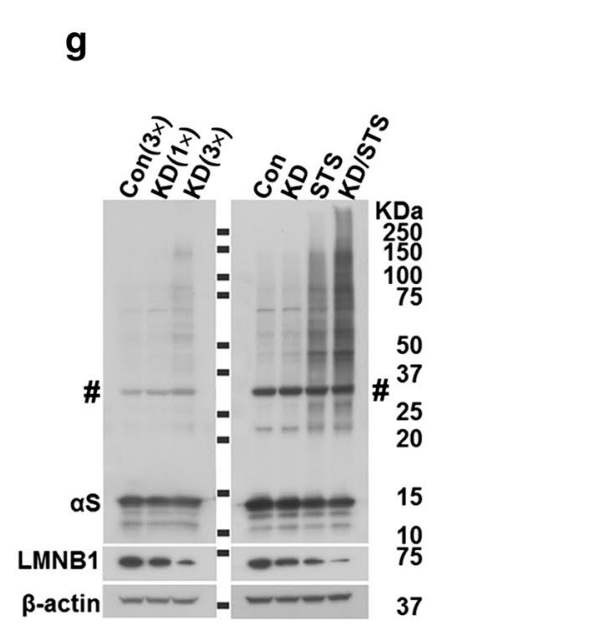

Fig. 3 Disruption of nuclear envelope plays an essential role in the rapid $\alpha \mathrm{S}$ aggregation during neuronal apoptosis. a, $\mathbf{b} \alpha \mathrm{S}$ aggregation in response to apoptosis induction predominantly occurred in nuclei rather than cytoplasm in live H4/V1S-SV2 cells. H4/V1S-SV2 cells cultured in Nunc ${ }^{\mathrm{TM}}$ Lab-Tek chambered cover glass system were induced to express H4/V1S-SV2 for 4 days, then maintained in media containing STS and Hoechst 33342 and subjected to time-lapse imaging using confocal fluorescence microscopy. A low magnification of live cell imaging demonstrates that about $94 \%$ cells (30-32) had oligomeric $\alpha \mathrm{S}$ (Olig. $\alpha \mathrm{S}$ ) predominantly in nuclei of cells (see red aster$i s k *$ in a) under $16 \mathrm{~h}$ of STS treatment. High magnification of live imaging of a single cell showed that the majority of $\alpha \mathrm{S}$ aggregates appears first in nuclei (arrow head in $\mathbf{b}$ at $18 \mathrm{~h}$ ) and then distributed to cytoplasm before finally being released to surrounding cells due to cell breakdown (arrows in b at 36 h). Scar bar: $10 \mu \mathrm{m}$. c, d Fractionation of cytoplasmic and nuclear proteins revealed the dynamic distribution of $\alpha \mathrm{S}$ aggregates and other proteins in apoptotic neurons. Differentiated BE(2)-M17D/3D5 cells with 5 days of $\alpha \mathrm{S}$ induction were, respectively, exposed to $25 \mathrm{nM}$ for $0,8,16$ and $24 \mathrm{~h}$ before harvest. c Nuclear and cytoplasm fractions were isolated and subjected to SDS-PAGE followed by western blotting. Dot blots were used to detect total $\alpha \mathrm{S}(\mathrm{T}-\alpha \mathrm{S})$ for evaluation of the dynamic changes of T- $\alpha \mathrm{S}$ in different fractions. $\alpha$-Tubulin and histone H3 were probed to confirm there was no contamination between cytoplasmic and nuclear fraction in non-treated control group. d Ponceau S staining was performed before immunostaining to demonstrate total protein in each

group. e, f Proaggregant nuclear factor(s) diffuse into cytoplasm with progression of apoptosis. Nuclear and cytoplasm fractions from null M17D neuroblastoma cells with 0,8 and $16 \mathrm{~h}$ of STS treatment were, respectively, isolated. Fresh recombinant $\alpha \mathrm{S}(10 \mu \mathrm{g})$ was incubated with the same amount of protein from each fraction for $30 \mathrm{~min}$ at $37{ }^{\circ} \mathrm{C}$. The same amount of recombinant $\alpha \mathrm{S}$ incubated with only cytoplasmic fraction buffer (CFB) or nuclear fraction buffer (NFB) was used as control. e Samples were subjected to SDS-PAGE followed by western blotting with monoclonal antibody to $\alpha \mathrm{S}$ (Syn1). Dot blotting was used to confirm the comparable level of input recombinant $\alpha \mathrm{S}$ in each sample. f Ponceau $\mathrm{S}$ staining was performed to demonstrate comparable levels of protein in all samples of cytoplasmic and nuclear fractions. $\mathrm{g}$ Disintegration of nuclear envelope is associated with rapid $\alpha \mathrm{S}$ aggregation in neuronal cells in response to apoptosis induction. Differentiated BE(2)-M17D/3D5 cells with 5 days of $\alpha \mathrm{S}$ induction infected with lentivirus carrying shRNA of LMNB1 and control vector were exposed to media with or without $25 \mathrm{nM}$ STS for $16 \mathrm{~h}$. Lentivirus infection was performed on the day 3 of culture. Left: one arbitrary unit $(1 \mathrm{x})$ or 3 units $(3 \mathrm{x})$ of lentivirus were applied to cells to obtain different extent of LMNB1 knockdown (KD). For control (Con), 3 units (3x) of lentivirus was used. Right: one arbitrary unit of lentivirus was used for both control (Con) and LMNB1 knockdown (KD). Cell lysates were subjected to SDSPAGE and western blotting. Number sign (\#) denotes a non-specific Syn1-immunoreactive band on western blots of lysates from BE(2)M17D/3D5 cells in $(\mathbf{c}, \mathbf{g})$ 

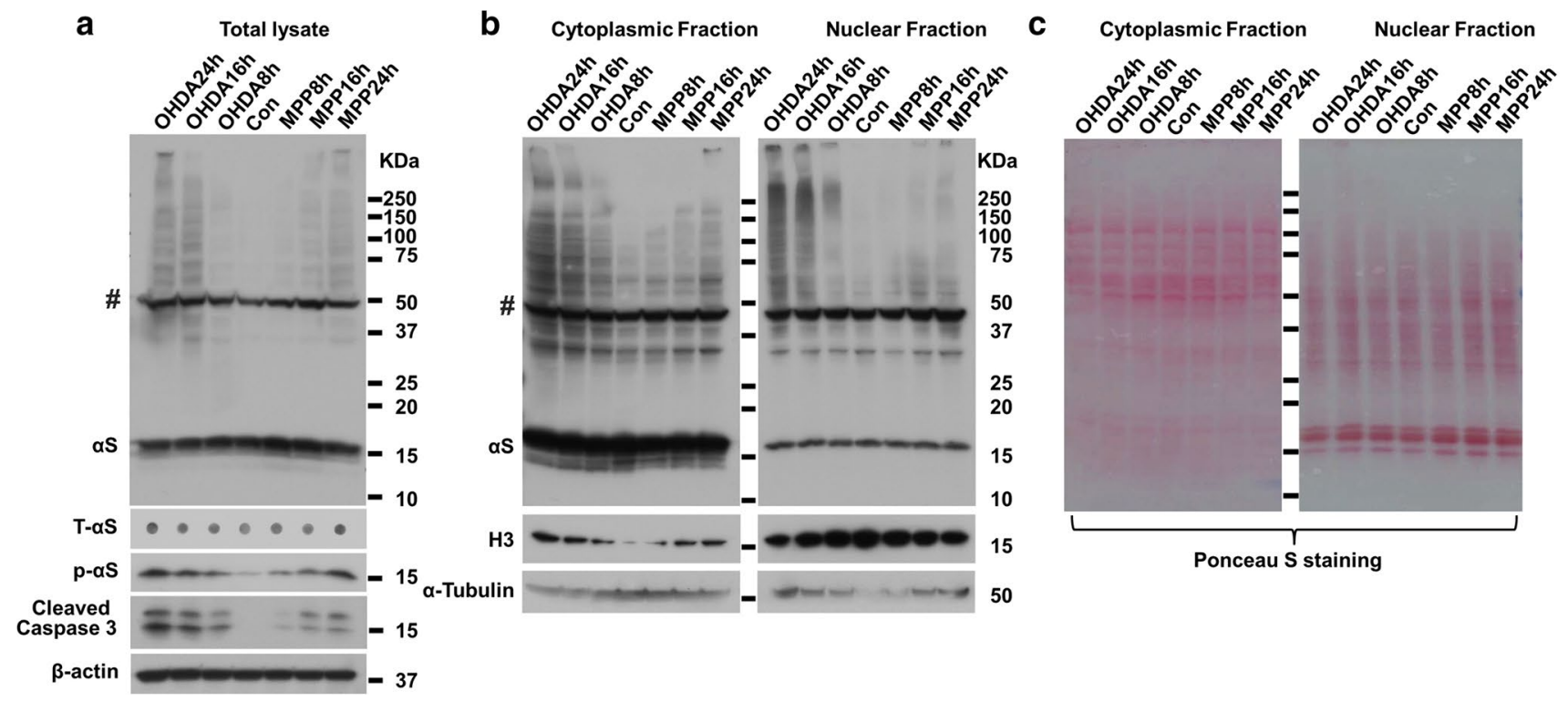

Fig. 4 Aggregation and phosphorylation of $\alpha \mathrm{S}$ as well as the distribution of $\alpha \mathrm{S}$ aggregates in neuronal cells are induced by neurotoxins MPP+ and 6OHDA. Differentiated BE(2)-M17D/3D5 cells with 5 days of $\alpha \mathrm{S}$ induction were, respectively, exposed to MPP+ or 6-6OHDA for 8,16 and $24 \mathrm{~h}$ before harvest. Cells without treatment were used as control (Con). Each group of cells was divided into two parts for extraction of total cell lysates or isolation of nuclear and cytoplasm fractions. Samples were subjected to SDS-PAGE followed by western blotting with antibodies to proteins of interest. Dot blots of cell lysates were used to detect the total $\alpha \mathrm{S}$ level $(\mathrm{T}-\alpha \mathrm{S})$. Molecu-

STS-induced apoptosis all had time-dependent increases of p- $\alpha$ S (Figs. 1b, d, 2a, d, e).

\section{Aggregation and phosphorylation of $\alpha \mathrm{S}$ in neuronal cultures exposed to other neurotoxins}

Because STS is not a toxin that triggers PD-related pathology in humans and animal models, we performed similar experiments in neuronal cultures exposed to other neurotoxins commonly used in PD research. Differentiated $\mathrm{BE}(2)-\mathrm{M} 17 \mathrm{D} / 3 \mathrm{D} 5$ cells overexpressing $\alpha \mathrm{S}$ were treated with 1-methyl-4-phenylpyridinium (MPP+) [36, 37] or 6-hydroxy-dopamine (6OHDA) [38, 39]. As expected, time-dependent aggregation and phosphorylation of $\alpha \mathrm{S}$ were observed in neuron cultures with apoptosis induced by both neurotoxins (Fig. 4a). Furthermore, nuclear and cytoplasmic fractionation demonstrated that (1) cytoplasmic fractions contained more monomeric $\alpha \mathrm{S}$ than nuclear fractions (Fig. 4b); (2) $\alpha \mathrm{S}$ aggregates that formed in nuclear fractions had higher molecular weight than those in cytoplasmic fractions; and (3) $\alpha S$ aggregates increased in a time-dependent manner upon induction of apoptosis in both nuclear and cytoplasmic fractions. The changes observed in $\alpha \mathrm{S}$ aggregation and phosphorylation lar weight standards were included as references. a Analysis of total lysates showed that aggregation and Serine 129 phosphorylation of $\alpha \mathrm{S}$ gradually increased with progression of apoptosis in neuronal cells treated with MPP+ or 6OHDA. b Fractionation of cytoplasmic and nuclear proteins revealed that dynamic changes in distribution of $\alpha \mathrm{S}$ aggregates and other proteins in neuronal cells induced by MPP+ or 6-6OHDA treated were similar to those induced by STS. c. Ponceau $\mathrm{S}$ staining was performed to demonstrate that cytoplasmic and nuclear fraction have comparable levels of total proteins

and subcellular distribution of $\alpha \mathrm{S}$ aggregates in $\mathrm{BE}(2)$ M17D/3D5 cells treated with MPP+ and 6OHDA were similar to those observed with STS, suggesting apoptosis may play a role in toxicity of other neurotoxins, at least in terms of their effects on $\alpha \mathrm{S}$ aggregation in neuronal cultures.

\section{Apoptotic bodies associated with disruption of nuclear membrane integrity contain $\alpha \mathrm{S}$ aggregates}

Because $\alpha \mathrm{S}$ aggregates increasingly formed during apoptosis and because $\alpha \mathrm{S}$ aggregation at later stages of apoptosis was associated with unresolvable high-molecularweight molecular species at the top of gel (Fig. 1b, c), we examined the morphology of $\alpha \mathrm{S}$ aggregates in cultures at late stages of apoptotic cell death. Thirty-six hours after STS treatment, differentiated BE(2)-M17D/3D5 cells were subjected to immunocytochemical staining with LB509 to detect $\alpha \mathrm{S}$ aggregates [40]. At this late stage of apoptosis, cells showed disrupted nuclear profiles and more $\alpha \mathrm{S}$ aggregation than that observed in intact nuclei at earlier stages of apoptosis (Fig. 5a). Of note, $\alpha \mathrm{S}$ aggregates were observed not only in apoptotic bodies, but also in smaller structures (arrowheads in Fig. 5a). These findings suggest that a range 
a

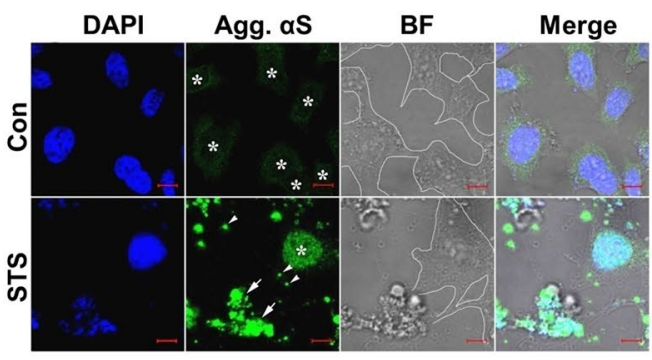

b

C
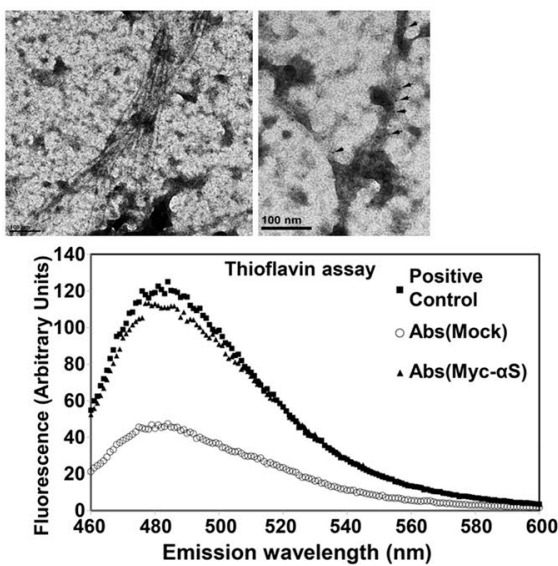

Fig. 5 Apoptotic bodies derived from neuronal cells with $\alpha \mathrm{S}$ overexpression contain $\alpha \mathrm{S}$ aggregates that are taken up by surrounding cells. a Apoptotic bodies with disrupted nuclear envelope have $\alpha \mathrm{S}$ aggregates. Differentiated BE(2)-M17D/3D5 cells with 5 days of $\alpha S$ expression were induced to enter late apoptotic stage by STS treatment for $36 \mathrm{~h}$ and then subjected to immunocytochemical staining with LB509 antibody and nuclear counterstaining with DAPI. Cells with intact nuclei are outlined (white line) in bright-field (BF) microscopy image. Signals of aggregated $\alpha S$ (Agg. $\alpha S$ ) in cells without STS treatment (Con) are enhanced to demonstrate the cell morphology since the laser setting used for imaging STS-treated cells was not visible in control cells. Arrows and arrowheads denote apoptotic bodies and other smaller structures. The asterisk (*) labeled the location of intact nuclei in both groups. b Ultrastructural evaluation of sarkosylinsoluble fractions prepared from apoptotic bodies. Apoptotic bodies were isolated from differentiated $\mathrm{BE}(2)-\mathrm{M} 17 \mathrm{D} / 3 \mathrm{D} 5$ cells with 5 days of $\alpha \mathrm{S}$ expression and $36 \mathrm{~h}$ of STS treatment and then subjected to fractionation to obtain Sarkosyl-insoluble fraction. (Left) Sarkosylinsoluble fraction adsorbed on EM grids and negatively stained with $5 \%$ uranyl acetate revealed filamentous assemblies of diameter about 8-10 nm. (Right) The filaments were decorated with $5 \mathrm{~nm}$ gold particles (arrows) by immunogold labeling using an anti- $\alpha \mathrm{S}$ antibody,

of $\alpha \mathrm{S}$ aggregates can be released into the extracellular milieu from apoptotic cells.

\section{Apoptotic bodies contain filamentous $\alpha \mathrm{S}$ aggregates}

Given the striking degree of $\alpha \mathrm{S}$ immunoreactivity in apoptotic bodies, we explored their ultrastructural characteristics to determine if apoptosis-associated $\alpha S$ was filamentous, as in Lewy bodies. Cell lysates from differentiated BE(2)-M17D/3D5 cells without STS treatment, thus verifying that they were assembled from $\alpha \mathrm{S}$. Similar filamentous structures were not detected in apoptotic bodies from null M17D cells (data not shown). Scale bar: $100 \mathrm{~nm}$. c Thioflavin T binding assay for sonicated apoptotic bodies derived from differentiated Myc- $\alpha \mathrm{S}$ cells and mock-transfected cells with $36 \mathrm{~h}$ of puromycin treatment to induce apoptosis. Apoptotic bodies containing $\alpha \mathrm{S}$-positive filaments shown in (b) were used as positive control. The PBS solution was used as blank. d Immunocytochemistry showed Myc immunoreactivity outside and inside $\alpha \mathrm{S}$-Flag cells treated with sonicated apoptotic bodies from Myc- $\alpha$ S cells. Similar findings are not observed in control cells treated with sonicated apoptotic bodies from null M17D cells. Z-stack imaging confirmed the internalization of Myc-positive $\alpha \mathrm{S}$ aggregates. e Neuronal cells can take up $\alpha \mathrm{S}$ aggregates released from surrounding apoptotic cells. $\alpha S$-Flag cells were co-cultured with Myc- $\alpha S$ or mock transfected M17D cells at equal density and subjected to differentiation for 5 days and then maintained in media with or without puromycin for another 5 days. After that, cells were fixed for immunocytochemical staining with antibodies to Myc and Flag and counterstaining with DAPI. Arrows and arrowheads denote Mycpositive aggregates from apoptotic bodies. Asterisk (*) and number sign (\#), respectively, marked the apoptotic bodies from Myc- $\alpha \mathrm{S}$ or mock transfected cells. Scale bar: $10 \mu \mathrm{m}$ for all pictures

and apoptotic bodies isolated from STS-treated differentiated BE(2)-M17D/3D5 cells or null M17D cells, were fractionated. Sarkosyl-insoluble fractions were processed for immunoelectron microscopy. Interestingly, filamentous structures were detected in BE(2)-M17D/3D5 cells derived from apoptotic bodies (Fig. 5b, left), but not in other samples (data not shown). The filaments were immunopositive for $\alpha \mathrm{S}$ (Fig. 5b, right), which suggests that filamentous $\alpha \mathrm{S}$ can be formed in apoptotic bodies of cells overexpressing $\alpha \mathrm{S}$. 
$\alpha S$ aggregates from apoptotic bodies can be taken up by neuronal cells

Since $\alpha \mathrm{S}$ aggregates in apoptotic bodies can be released upon disruption of the cell membrane, we investigated if aggregates of $\alpha \mathrm{S}$ can be internalized by surrounding cells as described in previous study [11]. To address this issue, we employed two different neuronal cell models derived from M17D neuroblastoma cell line. One overexpresses Myctagged $\alpha \mathrm{S}(\mathrm{Myc}-\alpha \mathrm{S})$ is neomycin resistant and sensitive to puromycin; the other overexpresses Flag-tagged $\alpha \mathrm{S}$ and is puromycin resistant, but sensitive to neomycin. Differentiated Myc- $\alpha S$ cells were treated with puromycin, which triggers apoptosis, for $36 \mathrm{~h}$ to produce Myc- $\alpha \mathrm{S}$ aggregates associated with apoptotic bodies [41]. Isolated apoptotic bodies were sonicated for a thioflavin $\mathrm{T}$ binding assay [30] to first confirm the formation of filamentous $\alpha \mathrm{S}$ (Fig. 5c), then added to differentiated $\alpha \mathrm{S}$-Flag cells. Apoptotic bodies from puromycin-treated differentiated mock transfectants were used as a control. After 3 days of exposure to sonicated apoptotic bodies, cells were fixed and immunolabeled with antibodies to Flag and Myc tags. Myc- $\alpha \mathrm{S}$ aggregates were observed on the cell surface and in the cytoplasm of most $\alpha \mathrm{S}$-Flag cells treated with Myc- $\alpha \mathrm{S}$ sonicated apoptotic bodies, but not in control cells (Fig. 5d). These findings suggest that Myc- $\alpha \mathrm{S}$ aggregates can bind to and be taken up by $\alpha S$-Flag cells.

To determine if neuronal cells can directly take up $\alpha \mathrm{S}$ aggregates released from surrounding apoptotic cells, $\alpha \mathrm{S}$-Flag cells were co-cultured with Myc- $\alpha \mathrm{S}$ or mock transfected M17D cells at equal density and subjected to differentiation for 5 days and maintained in media with or without puromycin for another 5 days before fixation and immunostaining. Apoptotic bodies, characterized by DAPI-positive nuclear debris, were observed in puromycinsensitive Myc- $\alpha \mathrm{S}$ cells bound to Flag- $\alpha \mathrm{S}$ cells (Fig. 5e). In addition, apoptotic bodies in the process of decomposition appeared to be internalized into puromycin-resistant $\alpha S$-Flag cells, suggesting that the apoptosis-induced $\alpha S$ aggregates can spread to surrounding cells in vitro. Furthermore, about $10 \pm 3 \%$ of the $\alpha$ S-Flag cells had internalized Myc-immunopositive particles that were co-labeled with Flag antibody (Fig. 5e), consistent with recruitment of endogenous $\alpha \mathrm{S}$-Flag protein into Myc- $\alpha \mathrm{S}$ seeds.

\section{Apoptosis-derived $\alpha \mathrm{S}$ aggregates can be taken up by cells in vivo}

To determine if apoptosis-induced $\alpha \mathrm{S}$ aggregates can be taken up by neighboring cells in vivo, apoptotic bodies from STS-treated differentiated BE(2)-M17D/3D5 cells with and without $\alpha \mathrm{S}$ overexpression were isolated and stereotaxically injected into somatosensory cortex and dorsal neostriatum of wild-type C57BL/6 mice at $\approx 12$ months of age following methods of Luk et al. [42]. Cell lysates from $\mathrm{BE}(2)-\mathrm{M} 17 \mathrm{D} / 3 \mathrm{D} 5$ cells with $\alpha \mathrm{S}$ overexpression, but without STS treatment, were included as a control. All injected materials were subjected to thioflavin $\mathrm{T}$ assay and SDSPAGE/western blots (Fig. 6a, b) to confirm the presence of $\alpha \mathrm{S}$ aggregates in the materials used for brain injection. After 1 week, brains were harvested, fixed and embedded in paraffin for immunohistochemical studies. Human $\alpha \mathrm{S}$ pathology was detected in the vicinity of the injected lysates from STS-treated cells in the form of neocortical neuronal perinuclear $\alpha \mathrm{S}$ deposits (Fig. 6d, ii1 in c), while thread-like and dot-like $\alpha \mathrm{S}$ deposits were detected in somatosensory cortex and dorsal neostriatum (Fig. 6c, insets). In contrast, cell lysates not treated with STS or those treated with STS, but not overexpressing $\alpha \mathrm{S}$, did not have neuronal cytoplasmic or neuritic $\alpha \mathrm{S}$ pathology (Fig. 6c, insets). These results suggest that $\alpha \mathrm{S}$ aggregates from apoptotic neurons can be taken up by neurons in vivo.

\section{Discussion}

Our study suggests that neuronal $\alpha \mathrm{S}$ aggregation may be triggered in some cases by proaggregant nuclear factor(s) associated with apoptosis. These initial aggregates may then serve as sources for $\alpha \mathrm{S}$ pathology in the immediate vicinity of the affected neurons, which may eventually propagate to more distant sites, possibly by cell-to-cell transmission. Although we demonstrated that filamentous $\alpha \mathrm{S}$ aggregates form quickly in apoptotic neurons, it remains to be determined whether this process occurs in PD and related disorders.

Apoptosis is thought to play a role in neuronal cell death in PD and related disorders. Specifically, markers of apoptosis have been demonstrated in postmortem brains of PD [14, 15], as well as animal models [16, 17] and cellular models of PD $[18,19]$. Moreover, it has been suggested that apoptosis is the most common type of neuronal death in PD and that there is a proapoptotic environment in the substantia nigra in PD [14]. Therefore, the proapoptotic environment and apoptotic neuronal death in PD and related disorders provide support for a role of apoptosisassociated proaggregant factor(s) in $\alpha \mathrm{S}$ aggregation.

Effective clearance mechanisms in the brain quickly remove apoptotic neurons and their breakdown products [43]. Under normal circumstance $\alpha \mathrm{S}$ aggregates would most likely be cleared and not propagate to adjacent cells. When neuronal death occurs in vulnerable neuronal populations in PD and related disorders, there may be incomplete clearance of breakdown products from apoptotic neurons and subsequent propagation of $\alpha \mathrm{S}$ aggregates. Aging is the major risk factor for PD, and it is associated with 


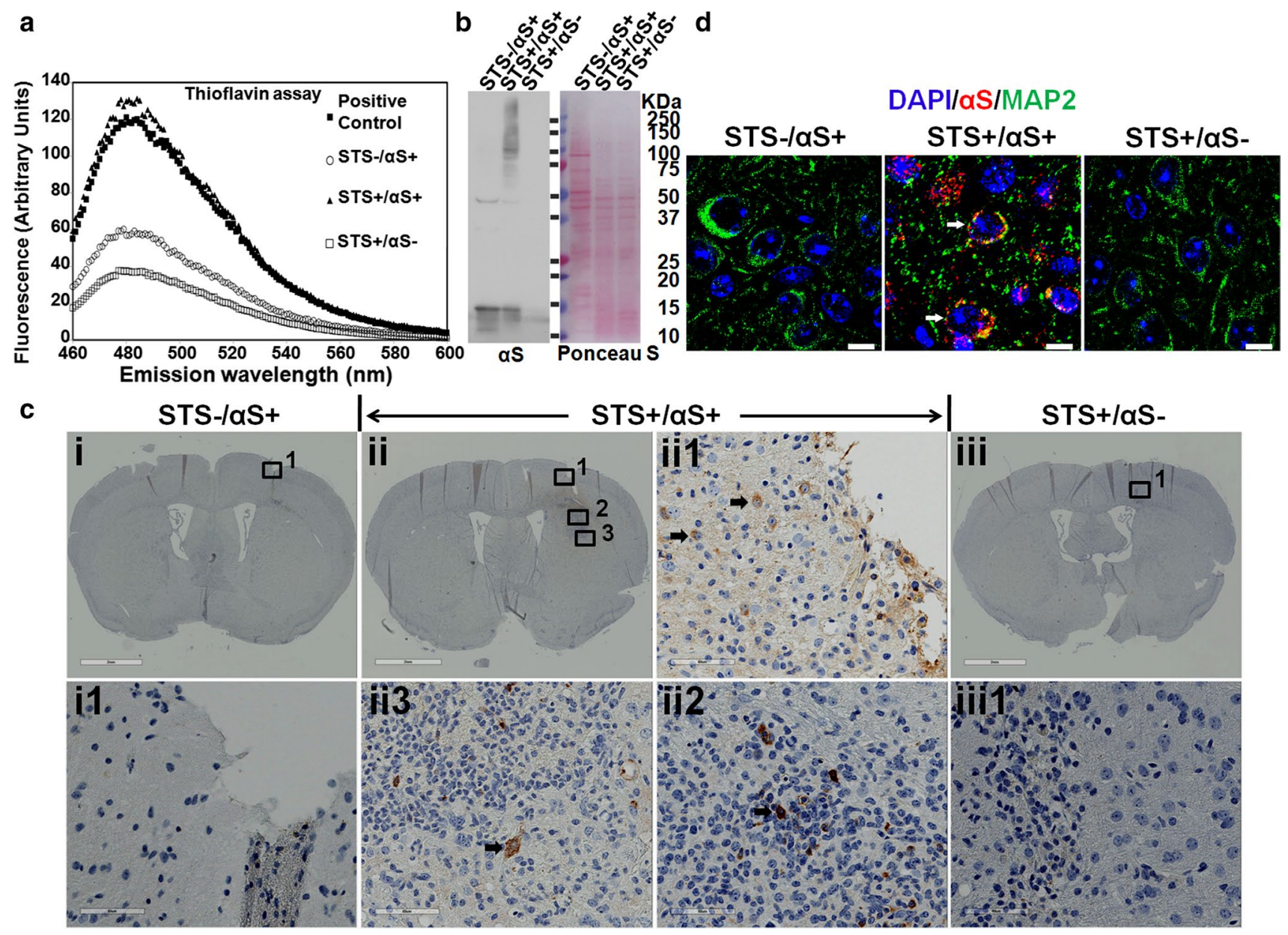

Fig. 6 Apoptotic bodies derived $\alpha \mathrm{S}$ aggregates can be taken up by neuronal cells in vivo upon inoculation into mouse brain. Apoptotic bodies from STS-treated BE(2)-M17D/3D5 cells with or without $\alpha \mathrm{S}$ induction, respectively, referred to as STS+/ $\alpha \mathrm{S}+$ and STS+l $\alpha \mathrm{S}-$, were isolated and injected into brains of mice around age of 12 months. Cell lysates from BE(2)-M17D/3D5 cells with $\alpha \mathrm{S}$ induction but without STS treatment was also included as another control (STS-/ $\alpha \mathrm{S}+$ ). All injected materials were subjected to a thioflavin $\mathrm{T}$ assay to confirm the formation of filamentous $\alpha \mathrm{S}$ and with SDSPAGE/western blotting to confirm SDS-insolubility of $\alpha \mathrm{S}$ aggregates.

decline in function of the immune system [44]. Thus, in the aged brain apoptosis-associated $\alpha \mathrm{S}$ aggregates may be more prone to propagation.

A caveat of our studies is that they were conducted in a human dopaminergic cell line that inducibly overexpresses $\alpha \mathrm{S}$. This issue is raised because a critical concentration of $\alpha S$ is required to initiate its assembly [33, 45], and the neuronal cultures used in many PD cell models have $\alpha \mathrm{S}$ overexpression. The rationale for using models with $\alpha \mathrm{S}$ overexpression is that familial PD with multiplication of the $\alpha \mathrm{S}$ gene $(S N C A)$ have increased expression of wild-type $\alpha \mathrm{S}$ [46-49] as well as severe $\alpha \mathrm{S}$ pathology [50]. Even in normal human aging and in older animal brains, $\alpha \mathrm{S}$ expression
Apoptotic bodies containing $\alpha \mathrm{S}$-positive filaments shown in Fig. $5 b$ were used as positive control for (a). Sections from the injected brain region were subjected to (c) immunohistochemical staining with LB509 to human $\alpha \mathrm{S}$ and (d) immunofluorescence staining with LB509 and MAP2 to confirm that neuronal uptake of human $\alpha \mathrm{S}$ aggregates can be only observed in mouse brain injected with apoptotic bodies (STS $+/ \alpha \mathrm{S}+$ ). Black arrows in (c) denote neuron-like cells with internalized $\alpha \mathrm{S}$ aggregates. White arrows in (d) denote $\mathrm{MAP} 2$ and human $\alpha \mathrm{S}$ aggregates positive neurons. Scale bar: $2 \mathrm{~mm}$ for $i, i i$ and iii, $60 \mu \mathrm{m}$ for $i 1, i i 1$ to ii3 and iiil in (c), $10 \mu \mathrm{m}$ for (d)

levels have been shown to be increased compared to younger individuals [51-54]. Although it remains unclear what concentration of $\alpha \mathrm{S}$ is critical for its aggregation in $\mathrm{PD}$ and related disorders, the fact that $\alpha \mathrm{S}$ aggregates can be observed in brains of aged animals and neurologically normal humans indicates that on a cell-by-cell basis there is a sufficient concentration of $\alpha \mathrm{S}$ to lead to aggregation even in normal individuals.

We propose that rapid formation of $\alpha \mathrm{S}$ aggregates in neurons undergoing apoptosis is a consequence of nucleocytoplasmic barrier disruption and the subsequent interaction between cytoplasmic $\alpha \mathrm{S}$ and proaggregant nuclear factor(s). Although previous studies have shown that $\alpha \mathrm{S}$ 
can be transported into the nucleus upon induction of oxidative stress either as an $\mathrm{N}$-terminal truncated form [55] or as full length form mediated by importin [56], these mechanisms are probably not relevant to our observations. First, using fluorescent complementation assays that are dependent upon integration of full-length tagged $\alpha \mathrm{S}$ molecules to monitor $\alpha \mathrm{S}$ oligomerization, we observed nuclear signals upon indication of apoptosis. Second, we did not detect evidence of truncated $\alpha \mathrm{S}$ in western blots of nuclear fractions. Thus, it does not appear that truncation of $\alpha \mathrm{S}$ is necessary for nuclear translocation in the setting of apoptosis. Third, our results showed that $\alpha \mathrm{S}$ aggregation associated with apoptosis is accompanied by degradation of nuclear envelope (Figs. 1, 2). Although we cannot completely exclude the possibility that some $\alpha \mathrm{S}$ may be transported into the nucleus by importin during apoptosis, this physiological process of nuclear pore complex transport may be minimal in a cell where there is considerable disruption of the nuclear envelope.

The $\alpha \mathrm{S}$ aggregates formed in apoptotic neurons share important features with pathological $\alpha \mathrm{S}$ from PD and related disorders, such as filamentous structures, thioflavin binding, serine- 129 phosphorylation and the ability to enter neuronal cells, suggesting similarities between $\alpha \mathrm{S}$ aggregates formed under in vitro and in vivo conditions.

Although we clearly demonstrated predominant nuclear localization of proaggregant factor(s) and cellular uptake of $\alpha \mathrm{S}$ aggregates formed upon disruption of nuclear envelope, we do not know the nature of nuclear proaggregant factor(s) and how $\alpha \mathrm{S}$ rapidly forms aggregates upon interaction with these factors. Since it has been shown that the loss of nuclear integrity is accelerated in post-mitotic cells in an age-dependent manner [57], it is possible that chronic nuclear "leakiness" of proaggregant factor(s) might also contribute to accumulation of $\alpha \mathrm{S}$ aggregates in brains of aged human [51].

Overall, our study suggests that a source of pathological $\alpha \mathrm{S}$ in PD and related disorders might be from apoptotic neurons in which $\alpha \mathrm{S}$ rapidly forms aggregates due to disruption of nuclear membrane and exposure of cytosolic $\alpha \mathrm{S}$ to proaggregant nuclear factor(s). Accordingly, at least some $\alpha \mathrm{S}$ aggregates might be a secondary phenomenon generated during neuronal apoptosis. The primary insult that leads to apoptosis is unknown; however, once triggered, the effects of apoptosis on $\alpha \mathrm{S}$ may accelerate a pathological cascade that eventually leads to local and more distant neurodegeneration. While it is important to determine the cause of neuronal apoptosis or leakiness of nuclear membrane that may possibly expose cytosolic $\alpha S$ to nuclear proaggregant factors in selectively vulnerable neuronal populations in PD and related disorders, finding ways to limit the effects of apoptosis on $\alpha \mathrm{S}$ aggregation, deposition, local uptake and propagation might significantly impact progression of the disease. The current observations suggest novel processes in the pathogenesis of $\mathrm{PD}$ and related disorders and may open the door to innovative treatments.

Acknowledgments The authors thank Monica Castanedes-Casey and Virginia Phillips for their histologic support. This study was supported by the National Institute of Health (P50-NS072187 and R01-NS073740), the Mangurian Foundation Lewy Body Dementia Program at Mayo Clinic (Dickson, Jiang and Yen).

\section{Compliance with ethical standards}

Conflict of interest All authors have no actual or potential conflicts of interest.

Open Access This article is distributed under the terms of the Creative Commons Attribution 4.0 International License (http://creativecommons.org/licenses/by/4.0/), which permits unrestricted use, distribution, and reproduction in any medium, provided you give appropriate credit to the original author(s) and the source, provide a link to the Creative Commons license, and indicate if changes were made.

\section{References}

1. Cookson MR (2005) The biochemistry of Parkinson's disease. Ann Rev Biochem 74:29-52

2. Acquatella-Tran Van Ba I, Imberdis T, Perrier V (2013) From prion diseases to prion-like propagation mechanisms of neurodegenerative diseases. Int J Cell Biol 2013:975832

3. Visanji NP, Brooks PL, Hazrati LN, Lang AE (2013) The prion hypothesis in Parkinson's disease: Braak to the future. Acta Neuropathol Comm 1:2

4. Braak H, Del Tredici K, Rub U, de Vos RA, Jansen Steur EN, Braak E (2003) Staging of brain pathology related to sporadic Parkinson's disease. Neurobiol Aging 24:197-211

5. Kordower JH, Chu Y, Hauser RA, Freeman TB, Olanow CW (2008) Lewy body-like pathology in long-term embryonic nigral transplants in Parkinson's disease. Nat Med 14:504-506

6. Li JY, Englund E, Holton JL, Soulet D, Hagell P, Lees AJ, Lashley T, Quinn NP, Rehncrona S, Bjorklund A et al (2008) Lewy bodies in grafted neurons in subjects with Parkinson's disease suggest host-to-graft disease propagation. Nat Med 14:501-503

7. Danzer KM, Kranich LR, Ruf WP, Cagsal-Getkin O, Winslow AR, Zhu L, Vanderburg CR, McLean PJ (2012) Exosomal cell-to-cell transmission of alpha synuclein oligomers. Mol Neurodegener 7:42

8. Desplats P, Lee HJ, Bae EJ, Patrick C, Rockenstein E, Crews L, Spencer B, Masliah E, Lee SJ (2009) Inclusion formation and neuronal cell death through neuron-to-neuron transmission of alpha-synuclein. Proc Natl Acad Sci USA 106:13010-13015

9. Luk KC, Kehm V, Carroll J, Zhang B, O'Brien P, Trojanowski JQ, Lee VM (2012) Pathological alpha-synuclein transmission initiates Parkinson-like neurodegeneration in nontransgenic mice. Science 338:949-953

10. Masuda-Suzukake M, Nonaka T, Hosokawa M, Oikawa T, Arai T, Akiyama H, Mann DM, Hasegawa M (2013) Prionlike spreading of pathological alpha-synuclein in brain. Brain 136:1128-1138

11. Volpicelli-Daley LA, Luk KC, Patel TP, Tanik SA, Riddle DM, Stieber A, Meaney DF, Trojanowski JQ, Lee VM (2011) Exogenous alpha-synuclein fibrils induce Lewy body pathology 
leading to synaptic dysfunction and neuron death. Neuron 72:57-71. doi:10.1016/j.neuron.2011.08.033

12. Guo JL, Lee VM (2014) Cell-to-cell transmission of pathogenic proteins in neurodegenerative diseases. Nat Med 20:130-138

13. Galvin JE, Lee VM, Trojanowski JQ (2001) Synucleinopathies:clinical and pathological implications. Arch Neurol 58:186-190

14. Lev N, Melamed E, Offen D (2003) Apoptosis and Parkinson's disease. Prog Neuropsychopharmacol Biol Psychiatry 27:245-250

15. Tatton WG, Chalmers-Redman R, Brown D, Tatton N (2003) Apoptosis in Parkinson's disease:signals for neuronal degradation. Ann Neurol 53(Suppl 3):S61-S70

16. He Y, Lee T, Leong SK (2000) 6-Hydroxydopamine induced apoptosis of dopaminergic cells in the rat substantia nigra. Brain Res 858:163-166

17. Tatton NA, Kish SJ (1997) In situ detection of apoptotic nuclei in the substantia nigra compacta of 1-methyl-4-phenyl-1,2,3,6tetrahydropyridine-treated mice using terminal deoxynucleotidyl transferase labelling and acridine orange staining. Neuroscience 77:1037-1048

18. Andersen JK (2001) Does neuronal loss in Parkinson's disease involve programmed cell death? Bioessays 23:640-646

19. Hartmann A, Hunot S, Michel PP, Muriel MP, Vyas S, Faucheux BA, Mouatt-Prigent A, Turmel H, Srinivasan A, Ruberg $M$ et al (2000) Caspase-3: a vulnerability factor and final effector in apoptotic death of dopaminergic neurons in Parkinson's disease. Proc Natl Acad Sci USA 97:2875-2880

20. Gentile A, Amadoro G, Corsetti V, Ciotti MT, Serafino A, Calissano P (2008) Spontaneous aggregation and altered intracellular distribution of endogenous alpha-synuclein during neuronal apoptosis. J Alzheimers Dis 13:151-160

21. Kalivendi SV, Cunningham S, Kotamraju S, Joseph J, Hillard CJ, Kalyanaraman B (2004) Alpha-synuclein up-regulation and aggregation during MPP + -induced apoptosis in neuroblastoma cells:intermediacy of transferrin receptor iron and hydrogen peroxide. J Biol Chem 279:15240-15247

22. Takahashi M, Ko LW, Kulathingal J, Jiang P, Sevlever D, Yen SH (2007) Oxidative stress-induced phosphorylation, degradation and aggregation of alpha-synuclein are linked to upregulated CK2 and cathepsin D. Eur J Neurosci 26:863-874

23. Ko LW, Ko HH, Lin WL, Kulathingal JG, Yen SH (2008) Aggregates assembled from overexpression of wild-type alpha-synuclein are not toxic to human neuronal cells. J Neuropathol Exp Neurol 67:1084-1096

24. Moussaud S, Malany S, Mehta A, Vasile S, Smith LH, McLean PJ (2015) Targeting alpha-synuclein oligomers by protein-fragment complementation for drug discovery in synucleinopathies. Expert Opin Ther Targets 19:589-603

25. Lotharius J, Barg S, Wiekop P, Lundberg C, Raymon HK, Brundin $P$ (2002) Effect of mutant alpha-synuclein on dopamine homeostasis in a new human mesencephalic cell line. J Biol Chem 277:38884-38894

26. Gan M, Moussaud S, Jiang P, McLean PJ (2015) Extracellular ATP induces intracellular alpha-synuclein accumulation via P2X1 receptor-mediated lysosomal dysfunction. Neurobiol Aging 36:1209-1220

27. Jiang P, Gan M, Ebrahim AS, Lin WL, Melrose HL, Yen SH (2010) ER stress response plays an important role in aggregation of alpha-synuclein. Mol Neurodegener 5:56

28. Jiang P, Gan M, Ebrahim AS, Castanedes-Casey M, Dickson DW, Yen SH (2013) Adenosine monophosphate-activated protein kinase overactivation leads to accumulation of alphasynuclein oligomers and decrease of neurites. Neurobiol Aging 34:1504-1515

29. Hristov M, Erl W, Linder S, Weber PC (2004) Apoptotic bodies from endothelial cells enhance the number and initiate the differentiation of human endothelial progenitor cells in vitro. Blood 104:2761-2766

30. Jiang P, Ko LW, Jansen KR, Golde TE, Yen SH (2008) Using leucine zipper to facilitate alpha-synuclein assembly. FASEB J 22:3165-3174

31. Kulathingal J, Ko LW, Cusack B, Yen SH (2009) Proteomic profiling of phosphoproteins and glycoproteins responsive to wildtype alpha-synuclein accumulation and aggregation. Biochim Biophys Acta 1794:211-224

32. Koh JY, Wie MB, Gwag BJ, Sensi SL, Canzoniero LM, Demaro J, Csernansky C, Choi DW (1995) Staurosporine-induced neuronal apoptosis. Exp Neurol 135:153-159

33. Shtilerman MD, Ding TT, Lansbury PT Jr (2002) Molecular crowding accelerates fibrillization of alpha-synuclein:could an increase in the cytoplasmic protein concentration induce Parkinson's disease? Biochemistry 41:3855-3860

34. Kihlmark M, Imreh G, Hallberg E (2001) Sequential degradation of proteins from the nuclear envelope during apoptosis. J Cell Sci 114:3643-3653

35. Fujiwara H, Hasegawa M, Dohmae N, Kawashima A, Masliah E, Goldberg MS, Shen J, Takio K, Iwatsubo T (2002) alpha-Synuclein is phosphorylated in synucleinopathy lesions. Nat Cell Biol 4:160-164

36. Eberhardt O, Schulz JB (2003) Apoptotic mechanisms and antiapoptotic therapy in the MPTP model of Parkinson's disease. Toxicol Lett 139:135-151

37. Gomez C, Reiriz J, Pique M, Gil J, Ferrer I, Ambrosio S (2001) Low concentrations of 1-methyl-4-phenylpyridinium ion induce caspase-mediated apoptosis in human SH-SY5Y neuroblastoma cells. J Neurosci Res 63:421-428

38. Hanrott K, Gudmunsen L, O'Neill MJ, Wonnacott S (2006) 6-hydroxydopamine-induced apoptosis is mediated via extracellular auto-oxidation and caspase 3-dependent activation of protein kinase Cdelta. J Biol Chem 281:5373-5382

39. Shimizu E, Hashimoto K, Komatsu N, Iyo M (2002) Roles of endogenous glutathione levels on 6-hydroxydopamine-induced apoptotic neuronal cell death in human neuroblastoma SK-N-SH cells. Neuropharmacology 43:434-443

40. Iwatsubo T (1999) Parkinson's disease, dementia with Lewy bodies, multiple system atrophy and alpha-synuclein. Rinsho Shinkeigaku 39:1285-1286

41. Constam DB, Tobler AR, Rensing-Ehl A, Kemler I, Hersh LB, Fontana A (1995) Puromycin-sensitive aminopeptidase. Sequence analysis, expression, and functional characterization. J Biol Chem 270:26931-26939

42. Luk KC, Kehm VM, Zhang B, O'Brien P, Trojanowski JQ, Lee VM (2012) Intracerebral inoculation of pathological alpha-synuclein initiates a rapidly progressive neurodegenerative alphasynucleinopathy in mice. J Exp Med 209:975-986

43. Devitt A, Marshall LJ (2011) The innate immune system and the clearance of apoptotic cells. J Leukoc Biol 90:447-457

44. Castelo-Branco C, Soveral I (2014) The immune system and aging: a review. Gynecol Endocrinol 30:16-22

45. Krishnan S, Chi EY, Wood SJ, Kendrick BS, Li C, Garzon-Rodriguez W, Wypych J, Randolph TW, Narhi LO, Biere AL et al (2003) Oxidative dimer formation is the critical rate-limiting step for Parkinson's disease alpha-synuclein fibrillogenesis. Biochemistry 42:829-837

46. Hadjigeorgiou GM, Xiromerisiou G, Gourbali V, Aggelakis K, Scarmeas N, Papadimitriou A, Singleton A (2006) Association of alpha-synuclein Rep1 polymorphism and Parkinson's disease: influence of Rep1 on age at onset. Mov Disord 21:534-539

47. Nishioka K, Hayashi S, Farrer MJ, Singleton AB, Yoshino H, Imai H, Kitami T, Sato K, Kuroda R, Tomiyama H et al (2006) Clinical heterogeneity of alpha-synuclein gene duplication in Parkinson's disease. Ann Neurol 59:298-309 
48. Pals P, Lincoln S, Manning J, Heckman M, Skipper L, Hulihan M, Van den Broeck M, De Pooter T, Cras P, Crook J et al (2004) alpha-Synuclein promoter confers susceptibility to Parkinson's disease. Ann Neurol 56:591-595

49. Singleton AB, Farrer M, Johnson J, Singleton A, Hague S, Kachergus J, Hulihan M, Peuralinna T, Dutra A, Nussbaum R et al (2003) alpha-Synuclein locus triplication causes Parkinson's disease. Science 302:841

50. Gwinn-Hardy K, Mehta ND, Farrer M, Maraganore D, Muenter M, Yen SH, Hardy J, Dickson DW (2000) Distinctive neuropathology revealed by alpha-synuclein antibodies in hereditary parkinsonism and dementia linked to chromosome 4p. Acta Neuropathol 99:663-672

51. Canron MH, Perret M, Vital A, Bezard E, Dehay B (2012) Agedependent alpha-synuclein aggregation in the Microcebus murinus lemur primate. Sci Reps 2:910

52. Chu Y, Kordower JH (2007) Age-associated increases of alphasynuclein in monkeys and humans are associated with nigrostriatal dopamine depletion: is this the target for Parkinson's disease? Neurobiol Dis 25:134-149
53. Jellinger KA (2004) Lewy body-related alpha-synucleinopathy in the aged human brain. J Neural Transm (Vienna) 111:1219-1235

54. Li W, Lesuisse C, Xu Y, Troncoso JC, Price DL, Lee MK (2004) Stabilization of alpha-synuclein protein with aging and familial parkinson's disease-linked A53T mutation. J Neurosci 24:7400-7409

55. Xu S, Zhou M, Yu S, Cai Y, Zhang A, Ueda K, Chan P (2006) Oxidative stress induces nuclear translocation of C-terminus of alpha-synuclein in dopaminergic cells. Biochem Biophys Res Comm 342:330-335

56. Ma KL, Song LK, Yuan YH, Zhang Y, Han N, Gao K, Chen NH (2014) The nuclear accumulation of alpha-synuclein is mediated by importin alpha and promotes neurotoxicity by accelerating the cell cycle. Neuropharmacology 82:132-142

57. D'Angelo MA, Raices M, Panowski SH, Hetzer MW (2009) Age-dependent deterioration of nuclear pore complexes causes a loss of nuclear integrity in postmitotic cells. Cell 136:284-295 